\title{
Associations between low- and high-dose oral fluconazole and pregnancy outcomes: 3 nested case-control studies
}

\author{
Anick Bérard PhD, Odile Sheehy MSc, Jin-Ping Zhao MD PhD, Jessica Gorgui MSc, Sasha Bernatsky MD PhD, \\ Cristiano Soares de Moura PhD, Michal Abrahamowicz PhD
}

Cite as: CMAJ 2019 February 19;191:E179-87. doi: 10.1503/cmaj.180963

See related article at www.cmaj.ca/lookup/doi/10.1503/cmaj.190079

\section{ABSTRACT \\ Background: While topical azoles are the first-line treatment for fungal infections, oral fluconazole is frequently used during pregnancy. We aimed to assess the effect of exposure to low and high doses of flu- conazole during pregnancy on the occur- rence of spontaneous abortions, major congenital malformations and stillbirths.}

Methods: Within the Quebec Pregnancy Cohort (1998-2015), we identified women exposed to low- ( $\leq 150 \mathrm{mg}$ ) and high-dose (> $150 \mathrm{mg}$ ) fluconazole, and women who were not exposed. For each case of spontaneous abortion or stillbirth, up to 5 controls were randomly selected using an incidence density sampling method matched on gestational age at diagnosis of spontaneous abortion or stillbirth (index date) and the year of the last menstrual period. For cases of major congenital malforma- tion, we considered all liveborn babies as controls. Generalized estimation equation models were used to analyze the 3 main outcomes separately.

Results: Within a cohort of 441949 pregnancies, 320868 pregnancies were included in the analyses of spontaneous abortions, 226599 of major congenital malformations and 7832 of stillbirths. Most (69.5\%) women exposed to fluconazole in pregnancy received the common single therapeutic dose of $150 \mathrm{mg}$ (low dose); the remainder received a dose of $>150 \mathrm{mg}$ (high dose). Use of oral fluconazole during early pregnancy was associated with an increased risk of spontaneous abortion compared with no exposure (adjusted odds ratio [OR] for 345 cases exposed to low-dose treatment 2.23, 95\% confidence interval [Cl]
1.96-2.54; adjusted OR for 249 cases exposed to high-dose treatment 3.20 , 95\% Cl 2.73-3.75). Exposure to fluconazole during the first trimester did not increase the risk of overall major congenital malformations; however, exposure to a high dose during the first trimester was associated with an increased risk of cardiac septal closure anomalies (adjusted OR 1.81, 95\% Cl 1.04-3.14; 13 exposed cases) compared with no exposure. No association was found between exposure to fluconazole during pregnancy and the risk of stillbirth.

Interpretation: Any maternal exposure to fluconazole during pregnancy may increase risk of spontaneous abortion and doses higher than $150 \mathrm{mg}$ during the first trimester may increase risk of cardiac septal closure anomalies.
$\mathbf{F}$

luconazole is a triazole antifungal agent that inhibits the fungal cytochrome P451 (CYP51) enzyme, which is essential for synthesis of ergosterol and the formation of fungal cell walls. ${ }^{1}$ In humans, CYP51 is necessary for synthesis of cholesterol, ${ }^{2}$ required by human embryo-fetal tissues. ${ }^{3}$ Oral fluconazole is prescribed at a single dose of $150 \mathrm{mg}$ to treat vulvovaginal candidiasis and at a higher dose for systemic fungal infections.

About $10 \%$ of pregnant women are affected by vulvovaginal candidiasis (the common yeast infection), ${ }^{4}$ a risk that is $2-10$ times higher than in nonpregnant women. ${ }^{5}$ Topical azoles are recommended as first-line treatment during pregnancy, ${ }^{6,7}$ but low-dose oral fluconazole is frequently used in pregnancy, given that vulvovaginal candidiasis in pregnancy may be more severe and treatment resistant. ${ }^{8,9}$

Treatment with high-dose fluconazole in pregnancy has been linked to a distinct pattern of craniofacial, skeletal and heart defects. ${ }^{10-13}$ Animal studies have confirmed the teratogenicity of fluconazole at high doses. ${ }^{14,15}$ Specifically, use of high-dose fluconazole during pregnancy has been linked to a pattern of major congenital malformations ${ }^{10-13}$ resembling the Antley-Bixler syndrome, a genetic disorder associated with reduced activity of CYP51 owing to genetic mutations. ${ }^{16}$ As such, use of high-dose fluconazole during pregnancy is contraindicated. ${ }^{17-19}$ 
We aimed to assess the effect of exposure to low- and highdose fluconazole during pregnancy on the occurrence of spontaneous abortions, major congenital malformations and stillbirths.

\section{Methods}

\section{Study participants}

We conducted 3 nested case-control studies using data from the Quebec Pregnancy Cohort. This is a population-based cohort with prospective data collection on all pregnancies covered by the Quebec Prescription Drug Insurance, from Jan. 1, 1998, to Dec. 31, 2015 , in the province of Quebec. ${ }^{20}$ The Quebec Pregnancy Cohort is updated every 3 years; the latest data available are from 2015. Individual-level information was obtained from province-wide databases and linked using unique personal identifiers. The Quebec Pregnancy Cohort was first constructed by identifying all pregnancies in the Régie de l'assurance maladie du Québec (RAMQ) and the Quebec hospitalization archives (Maintenance et Exploitation de Données pour l'Étude de la Clientèle HOspitalière [MEDÉCHO]) databases; the first day of the last menstrual period was used to define gestational age, which has been validated against ultrasound measurements in patients' charts. ${ }^{21}$ Gestational age is also provided by MED-ÉCHO and the Institut de la statistique du Québec (ISQ) at the end of pregnancy (delivery, spontaneous or induced abortion). Data on gestational age provided in both MEDÉCHO and the ISQ have been compared and found to have 99.1\% reliability. Prospective follow-up was available from 1 year before the last menstrual period, during pregnancy, and until Dec. 31, 2015 (Supplementary Figure S1, Appendix 1, available at www. cmaj.ca/lookup/suppl/doi:10.1503/cmaj.180963/-/DC1.)

The Quebec Pregnancy Cohort data sources included the medical claims database (RAMQ: outpatient diagnoses, procedures, women's and physicians' socioeconomic status), Quebec Prescription Drug Insurance database (drug name, start date, dosage, duration), hospitalization archive database (MED-ÉCHO: diagnoses and procedures), and Quebec Statistics database (patient sociodemographics, gestational age and birth weight). Given that pregnant women had to have medication insurance coverage from the RAMQ, data in the Quebec Pregnancy Cohort represent about 36\% of pregnant women aged between 15 and 45 years. ${ }^{22}$ The Quebec Pregnancy Cohort represents the entire stratum of the Quebec population of pregnant women who are insured for their drug plan by RAMQ, which ensures the study's internal validity. Validation studies have shown that pregnant women with public insurance (RAMQ) for their medications have characteristics and comorbidities similar to those who have private medication insurance, which ensures generalizability of the study findings. ${ }^{23}$ Furthermore, linkage between maternal and child data in the Quebec Pregnancy Cohort was possible more than $95 \%$ of the time..$^{24-27}$ Once a woman and her child are included in a study, we have access to all variables (available data); when data were missing for any of the sociodemographic variables, we used the accepted method of monotone multiple imputation ${ }^{28}$ (Supplementary Figure S2, Appendix 1).

We included pregnancies with continuous Quebec Prescription Drug Insurance coverage for $\geq 12$ months before and during pregnancy. We based analyses of spontaneous abortion on all pregnan- cies in the cohort, but based analyses of major congenital malformation on singleton live births, and stillbirth analyses of pregnancies with at least 20 gestational weeks. We excluded pregnancies exposed to known teratogens during the first trimester (0-14 completed weeks of gestation) as described by Kulaga and colleagues. ${ }^{29}$ For analyses of spontaneous abortion, we excluded women with induced abortions because we were interested in a pharmacologic effect with regard to pregnancy loss. We identified induced abortions by the International Classification of Diseases, 9th Revision (ICD-9) codes 635.0-637.9.

For analyses of associations with major congenital malformation, we excluded pregnancies that resulted in newborns with minor malformations alone, or with chromosomal abnormalities in the newborns, because these are unlikely to be related to medication use in pregnancy. For analyses of associations with stillbirth, only cases of fetal deaths with a birth weight of $\geq 500 \mathrm{~g}$ or a duration of $\geq 20$ weeks of gestation were included, because only those are registered in Canada; ${ }^{30}$ we also excluded pregnancies that ended with induced or spontaneous abortion (Figure 1 and Supplementary Figure S3, Appendix 1).

\section{Exposure to fluconazole}

We identified prescriptions for oral fluconazole filled from the Quebec Prescription Drug Insurance database, using timing of exposure determined by the dispensed date and duration of treatment. The relevant exposure time window for the analyses of spontaneous abortions was from the last menstrual period until the index date (defined as the gestational age of the spontaneous abortion or corresponding index date for matched controls) or a filled prescription with a duration that overlapped the last menstrual period. For analyses of associations with stillbirth, pregnancies were considered to be exposed if women had filled at least 1 prescription for oral fluconazole between the last menstrual period and the index date (defined as gestational age at diagnosis of stillbirth or corresponding index date for controls) or if they had filled a prescription with a duration that overlapped the last menstrual period. The relevant exposure time window for the analysis of major congenital malformations was the first trimester (organogenesis), which is the critical period in the development of the fetus, associated with most structural defects. ${ }^{31,32}$ Although the presence of major congenital malformations is usually noted at birth or in the first year of life, such malformations occur by the end of the first trimester. ${ }^{33}$

We stratified exposure to oral fluconazole during each relevant time window as low dose $(\leq 150 \mathrm{mg})$ and high dose $(>150 \mathrm{mg})$, using the cumulative dose in each period. We defined the comparator group as pregnancies with no exposure to fluconazole during the time window of interest. We used exposure to other antibiotics during the same time window as an active comparator, to take into account the underlying indication (considering potential indication bias).

We validated data on filled prescriptions in the Quebec Pregnancy Cohort, comparing them with maternal reports; we found the positive predictive value of prescription drug data to be $\geq 87 \%$ (95\% confidence interval $[\mathrm{Cl}] 70 \%-100 \%$ ) and the negative predictive value to be $\geq 92 \%(95 \% \mathrm{Cl} 86 \%-98 \%) \cdot{ }^{34} \mathrm{~A}$ copayment is required to fill a prescription in Quebec, which increases the likelihood that the medication received was taken. 


\section{Outcomes}

We identified cases of clinically detected spontaneous abortions from the RAMQ and MED-ÉCHO databases, using the World Health Organization ${ }^{35}$ and United Nations ${ }^{36}$ definitions, which have been used before and found to be valid. ${ }^{24,25,37}$ Thus, we included cases that occurred between $60 / 7$ and $196 / 7$ weeks of gestation.

We identified cases of major congenital malformation diagnosed in the first 6 months of life from the RAMQ and MED-ÉCHO databases and defined them according to ICD-9 and International Classification of Diseases, 10th Revision (ICD-10) codes, which have been validated against patient charts with high positive predictive value (78.1\%) and negative predictive value (94.2\%). All organ systems were considered, and high positive predictive values (more than $80 \%$ ) have also been reported for specific major congenital malformations. ${ }^{38}$

We identified cases of stillbirths from the RAMQ, MED-ÉCHO and ISQ databases. For analyses of stillbirth, we included only cases of fetal deaths with a birth weight of $\geq 500 \mathrm{~g}$ or a duration of $\geq 20$ weeks of gestation because only those are registered in Canada. ${ }^{30}$ These age or weight criteria have been found to be reliably reported in the ISQ database. ${ }^{21}$

For each case of spontaneous abortion or stillbirth, we randomly selected up to 5 controls using an incidence density sampling method matched on gestational age at diagnosis of spontaneous abortion or stillbirth (index date) and the year of the last menstrual period. For cases of major congenital malformation, we considered all live-births as controls, and thus did not do any sampling.

Diagnostic codes for spontaneous abortions, major congenital malformations and stillbirth are listed in Supplementary Table S4, Appendix 1.

\section{Statistical analysis}

Within the identified cohort, we conducted 3 nested case-control studies to quantify the association between exposure to fluconazole during pregnancy and the occurrence of either spontaneous abortion, major congenital malformation or stillbirth.

We considered the following potential confounders for all analyses: sociodemographic variables at the last menstrual period, including maternal age, receipt of social assistance during or 1 year before pregnancy (yes or no) and area of residence (urban or rural); maternal chronic comorbidities (6 mo prepregnancy), including hypertension, diabetes, asthma, epilepsy, depression, thyroid disorders and obesity, as well as the diagnosis of infection to adjust for potential indication bias; use of health care resources, including hospital admissions or emergency department visits (yes or no), and number of visits to a general practitioner and specialist physician (6 mo prepregnancy); lifestyle variables such as tobacco and alcohol dependence; and pregnancy-related variables, including use of folic acid, previous pregnancy, induced or spontaneous abortion in the year before the last menstrual period (yes or no). We also considered whether pregnant women were under the care of an obstetrician or gynecologist (yes or no), and whether other medications were used during pregnancy (besides fluconazole or antibiotics and medication used to identify comorbidities). Supplementary Table S5 in Appendix 1 lists the diagnostic codes (ICD-9 and ICD-10) and medications used for the covariates.

The unit of analysis was the pregnancy. We calculated means for continuous variables and proportions for dichotomous variables. We calculated crude and adjusted odds ratios (adjusted ORs) with $95 \% \mathrm{Cl}$ for each outcome separately. We used multivariable logistic regression with generalized estimating equations to estimate the

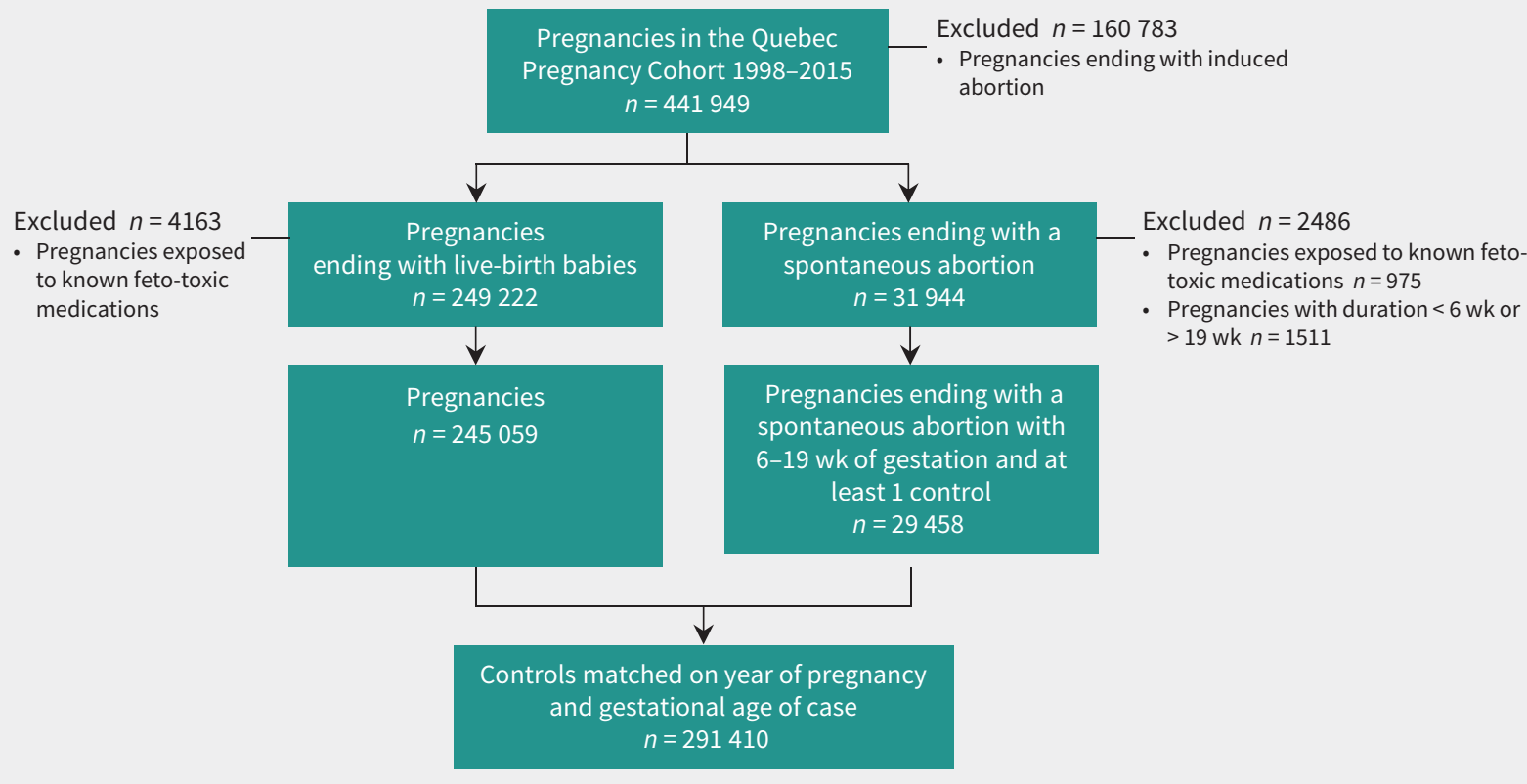

Figure 1: Selection of study population: spontaneous abortion. 
association between fluconazole exposure and risk of major congenital malformation, accounting for clustering by family (mother). We conducted no sampling for controls in this nested study; all liveborn controls were selected. We performed conditional logistic regression models to estimate the associations between spontaneous abortions and stillbirth, respectively, and fluconazole exposure, to respect the matching on gestational age and calendar year between cases and controls. Where data were missing for any of the sociodemographic variables, we used the method of monotone multiple imputation. ${ }^{28}$

We used SAS for all statistical analyses (SAS Institute Inc., version 9.2). Differences were significant when the $95 \% \mathrm{Cls}$ did not overlap 1.0 and when $p<0.05$ (2-tailed). We used the BenjaminiHochberg method ${ }^{39}$ to adjust for multiple testing.

\section{Ethics approval}

The study was approved by the Sainte-Justine Hospital Ethics Committee. The Commission d'accès à l'information du Québec authorized database linkages.

\section{Results}

From 441949 potentially eligible pregnancies, we included 320868 in the analyses of spontaneous abortions, 226599 in the analyses of major congenital malformations and 7832 in the analyses of stillbirths (Supplementary Figure S3 in Appendix 1 shows the selection process for each of the 3 main study outcomes). The most prevalent exclusions made on the basis of exposure to known teratogens were divalproex sodium (15.8\%), carbamazepine (12.4\%) and lithium (11.4\%).

Among pregnancies included in the analyses of spontaneous abortions, 1701 (0.53\%) were exposed to low-dose fluconazole and 891 of these $(0.28 \%)$ were exposed to high-dose fluconazole during early pregnancy (Figure 1). Mean gestational age at the time of spontaneous abortion was 16.6 weeks (standard deviation [SD] 3.1).

Adjusting for potential confounders, use of low- $(\geq 150 \mathrm{mg})$ and high-dose (> $150 \mathrm{mg}$ ) fluconazole during early pregnancy was associated with an increased risk of spontaneous abortion compared with no use (adjusted OR 2.23, 95\% Cl 1.96-2.54, 345 cases exposed to low-dose fluconazole; and adjusted OR 3.20, 95\% Cl 2.73-3.75, 249 cases exposed to high-dose fluconazole) (Table 1). Using the Benjamini-Hochberg method to account for multiple testing with a $10 \%$ false discovery rate, the association between use of low- and high-dose fluconazole during early pregnancy remained statistically significant $(p<0.01)$.

Exposure to other antibiotics during the same period was also associated with a $14 \%$ increased risk of spontaneous abortion (adjusted OR 1.14, 95\% Cl 1.10-1.17; 5864 exposed cases). Multivariate analyses showed that the risk of spontaneous abortion was higher among pregnancies in older mothers (adjusted OR 1.42, 95\% $\mathrm{Cl}$ 1.38-1.48 for women aged 35-39 years, and adjusted OR 2.73, $95 \% \mathrm{Cl} 2.59-2.88$ for women aged 40 years or older); those with tobacco dependence (adjusted OR 1.30, 95\% Cl 1.13-1.50) and alcohol dependence (adjusted OR 1.31, 95\% Cl 1.07-1.59). Intake of folic acid in the 6 months before the last menstrual period until index date was associated with reduced risk of spontaneous abortion (adjusted OR 0.63, 95\% Cl 0.58-0.68).
We identified the types of infections among the 32257 pregnancies with at least 1 diagnosis of infection (Supplementary Table S1, Appendix 1), which we compared between cases and controls (Supplementary Table S2, Appendix 1). Overall, 32257 pregnancies had at least 1 diagnosis of infection (Supplementary Table S1, Appendix 1). Urinary tract infections were the most prevalent (9370), followed by rare diseases resulting from viruses and chlamydiae (7355), and mycoses (3702) (Supplementary Table S1, Appendix 1). These were also more prevalent among cases of spontaneous abortion than among controls (Supplementary Table S2, Appendix 1).

Use of low-dose fluconazole during the first trimester did not increase the risk of overall major congenital malformation or specific organ system malformations compared with no exposure (Table 2 and Table 3). However, use of high-dose fluconazole during the first trimester was associated with an increased risk of anomalies of cardiac septal closure (adjusted OR 1.81, 95\% Cl 1.043.14; 13 exposed cases) compared with no exposure (Table 3). In our study, 913 pregnancies were exposed to low-dose fluconazole ( $\leq 150 \mathrm{mg}$ ), and 400 pregnancies to $>150 \mathrm{mg}$ fluconazole during the first trimester. Patients on the low dose took fluconazole 100$150 \mathrm{mg} / \mathrm{d}$ only once (1.0 dose, SD 0.1); those on the high dose (> $150 \mathrm{mg} / \mathrm{d}$ ) took, on average, 4.5 doses (SD 1.3), which means that pregnant women on fluconazole took either 1 dose for 1 day only, or took more than 3 doses on 3-4 separate days. Cases of congenital malformation among users of fluconazole during the first trimester are presented in Supplementary Table S3 in Appendix 1.

No association was found between exposure to low-dose or high-dose fluconazole during pregnancy and the risk of stillbirth (Table S6, Appendix 1).

\section{Interpretation}

Our nested case-control studies within a large population-based pregnancy cohort showed that fluconazole exposure (any dose) during early pregnancy is associated with an increased risk of spontaneous abortion, and use of high-dose fluconazole in the first trimester is associated with an increased risk of septal closure anomalies. Although this is consistent with animal studies, it could also be a chance finding or a result of unmeasured confounding. Therefore, this study requires replication. We found that use of antibiotics during pregnancy was independently associated with the risk of spontaneous abortion, which is consistent with the results of a previous study. ${ }^{37}$

Our findings pertaining to spontaneous abortion and stillbirth are consistent with 2 Danish nationwide cohort studies. ${ }^{40,41}$ Both studies found no association between exposure to fluconazole, regardless of dosage, and stillbirth. However, Mølgaard-Nielsen and colleagues ${ }^{40}$ showed that more spontaneous abortions occurred among women exposed to oral fluconazole than in those given topical azoles (hazard ratio $1.62,95 \% \mathrm{Cl} 1.26-2.07,130$ exposed cases). These authors identified a significantly increased risk of spontaneous abortion among patients exposed to lower doses of fluconazole but not in those exposed to higher doses, likely owing to their limited sample size. ${ }^{40}$

Within our cohort, a substantial number of women were exposed to fluconazole, and we found a significantly increased risk of spontaneous abortion among groups exposed to low- and high-dose fluconazole, which has not been observed in previous studies that 
Table 1: Association between use of oral fluconazole and other antibiotics during early pregnancy, as well as other relevant variables, and risk of spontaneous abortion*

\begin{tabular}{|c|c|c|c|c|}
\hline \multirow[b]{2}{*}{ Variable } & \multicolumn{2}{|c|}{ No. of pregnancies } & \multicolumn{2}{|c|}{ OR $(95 \% \mathrm{CI})$} \\
\hline & $\begin{array}{c}\text { Cases, } n(\%) \dagger \\
n=29458\end{array}$ & $\begin{array}{c}\text { Controls, } n(\%) \dagger \\
n=291410\end{array}$ & Crude & Adjusted $\ddagger$ \\
\hline \multicolumn{5}{|l|}{ Exposure to medications from LMP to index date $\S$} \\
\hline Fluconazole, low dose ( $\leq 150 \mathrm{mg}$ ) & $345(1.2)$ & $1356(0.5)$ & $2.51(2.21-2.85)$ & $2.23(1.96-2.54)$ \\
\hline Fluconazole, high dose (> $150 \mathrm{mg}$ ) & $249(0.9)$ & $642(0.2)$ & $3.91(3.26-4.45)$ & $3.20(2.73-3.75)$ \\
\hline Other antibiotics & $5864(19.9)$ & $47387(16.3)$ & $1.23(1.19-1.27)$ & $1.14(1.10-1.17)$ \\
\hline $\begin{array}{l}\text { Exposure to folic acid in } 6 \text { mo before LMP and until index } \\
\text { date (yes v. no) }\end{array}$ & $886(3.0)$ & $12271(4.2)$ & $0.70(0.65-0.76)$ & $0.63(0.58-0.68)$ \\
\hline No. of other prescribed medications, $₫$ mean \pm SD & $0.7 \pm 1.2$ & $0.6 \pm 1.1$ & $1.02(1.01-1.04)$ & $0.98(0.97-0.99)$ \\
\hline No other prescribed medication & $18038(61.2)$ & $181031(62.1)$ & Ref. & Ref. \\
\hline 1 other prescribed medication & $6614(22.5)$ & $70674(24.3)$ & $0.93(0.90-0.96)$ & $0.89(0.86-0.92)$ \\
\hline 2 or more other prescribed medications & $4806(16.3)$ & $39705(13.6)$ & $1.15(1.11-1.19)$ & $0.98(0.95-1.02)$ \\
\hline \multicolumn{5}{|l|}{ Demographic characteristics at LMP } \\
\hline Maternal age (yr), mean \pm SD & $29.3 \pm 6.5$ & $28.5 \pm 5.7$ & $1.03(1.02-1.03)$ & $1.03(1.03-1.03)$ \\
\hline $15-34$ & $22489(76.3)$ & $244961(84.1)$ & Ref. & Ref. \\
\hline $35-39$ & $4787(16.3)$ & $37554(12.9)$ & $1.39(1.34-1.44)$ & $1.42(1.38-1.48)$ \\
\hline $40+$ & $2182(7.4)$ & $8895(3.1)$ & $2.68(2.54-2.82)$ & $2.73(2.59-2.88)$ \\
\hline Welfare recipient (yes v. no) & $7621(25.9)$ & $66738(22.9)$ & $1.18(1.14-1.21)$ & $1.10(1.07-1.13)$ \\
\hline Urban dweller (yes v. no) & $24300(82.5)$ & $240893(82.7)$ & $1.00(0.97-1.03)$ & $0.98(0.94-1.00)$ \\
\hline \multicolumn{5}{|l|}{ Use of health services in 6 mo before LMP** } \\
\hline Emergency visit or hospital admission (yes v. no) & $7971(27.1)$ & $106023(34.38)$ & $1.30(1.26-1.33)$ & $1.07(1.03-1.11)$ \\
\hline No. of visits to GP, mean \pm SD & $2.8 \pm 4.2$ & $2.2 \pm 3.4$ & $1.01(1.01-1.01)$ & $1.02(1.01-1.02)$ \\
\hline No visit to GP & $9627(32.7)$ & $112635(38.7)$ & Ref. & Ref. \\
\hline 1 visit to GP & $5118(17.4)$ & $55124(18.9)$ & $1.09(1.05-1.13)$ & $1.07(1.03-1.11)$ \\
\hline $2-4$ visits to $G P$ & $8701(29.5)$ & $81228(27.9)$ & $1.23(1.19-1.26)$ & $1.14(1.10-1.18)$ \\
\hline 5 or more visits to GP & $6012(20.4)$ & $42423(14.6)$ & $1.64(1.59-1.70)$ & $1.35(1.29-1.41)$ \\
\hline No. of visits to specialist physician, mean \pm SD & $2.1 \pm 4.7$ & $1.6 \pm 3.8$ & $0.96(0.96-0.97)$ & $0.98(0.97-0.99)$ \\
\hline No visit to specialist physician & $15398(52.3)$ & $166272(57.1)$ & Ref. & Ref. \\
\hline 1 visit to specialist physician & $4379(14.9)$ & $44796(15.4)$ & $1.06(1.02-1.10)$ & $0.98(0.94-1.02)$ \\
\hline $2-4$ visits to specialist physician & 5485 (18.6) & $49453(17.0)$ & $1.19(1.15-1.23)$ & $1.02(0.98-1.05)$ \\
\hline 5 or more visits to specialist physician & $4196(14.2)$ & $30889(10.6)$ & $1.43(1.37-1.48)$ & $1.14(1.09-1.19)$ \\
\hline \multicolumn{5}{|l|}{$\begin{array}{l}\text { At least } 1 \text { diagnosis (in } 6 \text { mo before LMP and until index date) } \\
\text { (yes v. no) }\end{array}$} \\
\hline Infection & 3509 (11.9) & $27748(9.9)$ & $1.19(1.14-1.24)$ & $1.02(0.98-1.07)$ \\
\hline Tobacco dependence & $290(1.0)$ & $1569(0.5)$ & $1.78(1.56-2.03)$ & $1.30(1.13-1.50)$ \\
\hline Alcohol dependence & $162(0.6)$ & $669(0.2)$ & $2.25(1.88-2.71)$ & $1.31(1.07-1.59)$ \\
\hline Pregnancy in yr before LMP (yes v. no) & $2302(7.8)$ & $15449(5.3)$ & $1.50(1.43-1.57)$ & $1.37(1.30-1.44)$ \\
\hline \multicolumn{5}{|l|}{$\begin{array}{l}\text { Maternal comorbidities in } 6 \text { mo before LMP and until index } \\
\text { date }\end{array}$} \\
\hline Hypertension (yes v. no) & $657(2.2)$ & $5284(1.8)$ & $1.22(1.12-1.33)$ & $1.00(0.92-1.09)$ \\
\hline Diabetes (yes v. no) & $584(2.0)$ & $6851(2.4)$ & $0.73(0.67-0.80)$ & $0.71(0.65-0.78)$ \\
\hline Asthma (yes v. no) & $3382(11.5)$ & $27518(9.4)$ & $1.20(1.15-1.25)$ & $1.07(1.02-1.11)$ \\
\hline Epilepsy (yes v. no) & $352(1.2)$ & $2056(0.7)$ & $1.64(1.45-1.85)$ & $1.20(1.06-1.36)$ \\
\hline Depression (yes v. no) & $4959(16.8)$ & $32480(11.2)$ & $1.61(1.55-1.66)$ & $1.37(1.32-1.42)$ \\
\hline Thyroid disorders (yes v. no) & $1202(4.1)$ & $13959(4.8)$ & $0.78(0.73-0.83)$ & $0.75(0.71-0.80)$ \\
\hline \multicolumn{5}{|c|}{$\begin{array}{l}\text { Note: } \mathrm{Cl}=\text { confidence interval, } \mathrm{GP}=\text { general practitioner, } \mathrm{LMP}=\text { last menstrual period, } \mathrm{OR}=\text { odds ratio, Ref. }=\text { reference category, } \mathrm{SD}=\text { standard deviation. } \\
\text { *Mean proportion or percentage differences between cases and controls were all statistically significant with } p<0.01 \text { except for the proportion of rural dwellers. } \\
\text { tUnless stated otherwise (no. and percentages represent "yes" response where indicated). } \\
\text { tAdjusted OR obtained from multivariate conditional logistic regression model, adjusted for all variables included in the table. } \\
\text { SIndex date is defined as gestational age at the date of diagnosis of spontaneous abortion. } \\
\text { IBesides fluconazole or antibiotics and medication used to identify comorbidities. } \\
\text { **Except where indicated. }\end{array}$} \\
\hline
\end{tabular}


Table 2: Association between use of high- and low-dose fluconazole during first trimester, as well as other relevant variables, and risk of major congenital malformations*

\begin{tabular}{|c|c|c|c|c|}
\hline \multirow[b]{2}{*}{ Variable } & \multicolumn{2}{|c|}{ No. of pregnancies } & \multicolumn{2}{|c|}{ OR $(95 \% \mathrm{Cl})$} \\
\hline & $\begin{array}{c}\text { Cases, } n(\%) \dagger \\
n=19488\end{array}$ & $\begin{array}{c}\text { Controls, } n(\%) \dagger \\
n=207111\end{array}$ & Crude & Adjusted $\ddagger$ \\
\hline \multicolumn{5}{|l|}{ Exposure to medications during first trimester } \\
\hline Fluconazole, low dose ( $\leq 150 \mathrm{mg}$ ) & $92(0.5)$ & $821(0.4)$ & $1.19(0.96-1.48)$ & $1.08(0.87-1.34)$ \\
\hline Fluconazole, high dose (> 150 mg) & $50(0.3)$ & $350(0.2)$ & $1.51(1.12-2.03)$ & $1.30(0.97-1.75)$ \\
\hline Other antibiotics & $2879(14.8)$ & $28539(13.8)$ & $1.08(1.04-1.13)$ & $1.01(0.97-1.06)$ \\
\hline $\begin{array}{l}\text { Exposure to folic acid in } 6 \text { mo before LMP and } \\
\text { until index date§ }\end{array}$ & $943(4.8)$ & $7435(3.4)$ & $1.36(1.27-1.46)$ & $1.20(1.12-1.29)$ \\
\hline $\begin{array}{l}\text { No. of other prescribed medications, } \uparrow \text { mean } \pm \\
\text { SD }\end{array}$ & $0.6 \pm 1.0$ & $0.5 \pm 0.9$ & $1.09(1.08-1.11)$ & $1.06(1.04-1.07)$ \\
\hline No other prescribed medication & $12358(63.4)$ & $137449(66.4)$ & Ref. & Ref. \\
\hline 1 other prescribed medication & $4775(24.5)$ & $749344(23.8)$ & $1.02(1.04-1.11)$ & $1.04(1.01-1.08)$ \\
\hline 2 or more other prescribed medications & $2355(12.1)$ & $20318(9.8)$ & $1.29(1.23-1.35)$ & $1.15(1.10-1.21)$ \\
\hline \multicolumn{5}{|l|}{ Demographic characteristics at LMP } \\
\hline Maternal age (yr), mean \pm SD & $28.2 \pm 5.6$ & $28.2 \pm 5.6$ & $1.00(1.00-1.00)$ & $1.00(1.00-1.00)$ \\
\hline $15-34$ & $16677(85.6)$ & $178027(86.0)$ & Ref. & Ref. \\
\hline $35-39$ & $2297(11.8)$ & $24011(11.6)$ & $1.02(1.04-1.11)$ & $1.00(0.95-1.04)$ \\
\hline $40+$ & $514(2.6)$ & $5073(2.4)$ & $1.29(1.23-1.35)$ & $1.03(0.94-1.13)$ \\
\hline Welfare recipient (yes v. no) & $4632(23.8)$ & $47563(23.0)$ & $1.04(1.01-1.08)$ & $1.00(0.96-1.04)$ \\
\hline Urban dweller (yes v. no) & $16316(83.7)$ & $170279(82.2)$ & $1.11(1.07-1.16)$ & $1.11(1.06-1.15)$ \\
\hline \multicolumn{5}{|l|}{ Use of health services in 6 mo before LMP $P^{\star \star}$} \\
\hline No. of visits to GP, mean \pm SD & $1.7 \pm 2.3$ & $1.6 \pm 2.2$ & $1.01(1.01-1.02)$ & $0.99(0.98-1.00)$ \\
\hline No visit to GP & $7212(37.0)$ & $79647(38.5)$ & Ref. & Ref. \\
\hline 1 visit to GP & $4788(24.6)$ & $50766(24.5)$ & $1.04(1.00-1.08)$ & $0.99(0.95-1.03)$ \\
\hline $2-4$ visits to GP & $5655(29.0)$ & $58713(28.3)$ & $1.06(1.02-1.10)$ & $0.95(0.91-0.99)$ \\
\hline 5 or more visits to GP & $1833(9.4)$ & $17985(8.7)$ & $1.12(1.06-1.18)$ & $0.91(0.86-0.97)$ \\
\hline No. of visits to specialist physician, mean \pm SD & $1.4 \pm 2.8$ & $1.3 \pm 2.8$ & $1.01(1.01-1.02)$ & $1.00(0.99-1.00)$ \\
\hline No visit to specialist physician & $10709(55.0)$ & $119452(57.7)$ & Ref. & Ref. \\
\hline 1 visit to specialist physician & $3541(18.2)$ & $37511(18.1)$ & $1.05(1.01-1.09)$ & $1.01(0.97-1.05)$ \\
\hline $2-4$ visits to specialist physician & $3533(18.1)$ & $34509(16.7)$ & $1.14(1.10-1.19)$ & $1.03(0.99-1.08)$ \\
\hline 5 or more visits to specialist physician & $1705(8.7)$ & $15639(7.5)$ & $1.21(1.15-1.28)$ & $0.98(0.92-1.04)$ \\
\hline Emergency visit or hospital admission (yes v. no) & $4378(22.5)$ & $39235(18.9)$ & $1.24(1.19-1.28)$ & $1.20(1.15-1.25)$ \\
\hline $\begin{array}{l}\text { Supervision of pregnancy by an obstetrician } \\
\text { (yes v. no) }\end{array}$ & $2680(13.7)$ & $24588(11.9)$ & $1.18(1.13-1.23)$ & $1.12(1.08-1.18)$ \\
\hline Previous pregnancy in yr before LMP (yes v. no) & $1862(9.5)$ & $18023(8.7)$ & $1.11(1.05-1.16)$ & $1.04(0.99-1.10)$ \\
\hline \multicolumn{5}{|c|}{ Maternal comorbidities in 6 mo before LMP and until index date } \\
\hline Infection & $1936(9.9)$ & $19567(9.4)$ & $1.06(1.00-1.11)$ & $1.01(0.96-1.06)$ \\
\hline Hypertension & $441(2.3)$ & $3392(1.6)$ & $1.38(1.25-1.53)$ & $1.23(1.11-1.36)$ \\
\hline Diabetes & $525(2.7)$ & $3544(1.7)$ & $1.59(1.45-1.74)$ & $1.38(1.26-1.52)$ \\
\hline Asthma & $1942(10.0)$ & $18587(9.0)$ & $1.12(1.06-1.18)$ & $1.06(1.00-1.11)$ \\
\hline Epilepsy & $170(0.9)$ & $1209(0.6)$ & $1.49(1.27-1.76)$ & $1.25(1.06-1.47)$ \\
\hline Depression or anxiety & $2366(12.4)$ & $21582(10.4)$ & $1.18(1.13-1.24)$ & $1.11(1.06-1.17)$ \\
\hline Thyroid disorders & $911(4.7)$ & $8045(3.9)$ & $1.21(1.13-1.30)$ & $1.13(1.06-1.22)$ \\
\hline Tobacco dependence & $122(0.6)$ & $962(0.5)$ & $1.34(1.11-1.62)$ & $1.21(1.00-1.47)$ \\
\hline Alcohol dependence & $51(0.3)$ & $425(0.2)$ & $1.28(0.96-1.71)$ & $1.09(0.81-1.46)$ \\
\hline
\end{tabular}


Table 3: Use of fluconazole during the first trimester and risk of major congenital malformations overall and by organ system

\section{Organ system}

Any major congenital malformation

Exposure during first trimester

Nonexposed

Exposed to $\leq 150 \mathrm{mg}$ fluconazole

Exposed to $>150 \mathrm{mg}$ fluconazole

\section{Nervous}

Exposure during first trimester

Nonexposed

Exposed to $\leq 150 \mathrm{mg}$ fluconazole

Exposed to $>150 \mathrm{mg}$ fluconazole

Eyes

Exposure during first trimester

Nonexposed

Exposed to $\leq 150 \mathrm{mg}$ fluconazole

Exposed to $>150 \mathrm{mg}$ fluconazole

\section{Cardiac septal}

Exposure during first trimester

Nonexposed

Exposed to $\leq 150 \mathrm{mg}$ fluconazole

Exposed to $>150 \mathrm{mg}$ fluconazole

\section{Digestive}

Exposure during first trimester

Nonexposed
Exposed to $\leq 150 \mathrm{mg}$ fluconazole
Exposed to $>150 \mathrm{mg}$ fluconazole

\section{Genital}

Exposure during first trimester

\section{Nonexposed}

Exposed to $\leq 150 \mathrm{mg}$ fluconazole

Exposed to $>150 \mathrm{mg}$ fluconazole

\section{Urinary}

Exposure during first trimester

Nonexposed

Exposed to $\leq 150 \mathrm{mg}$ fluconazole

Exposed to $>150 \mathrm{mg}$ fluconazole

\section{Musculoskeletal}

Exposure during first trimester

Nonexposed
Exposed to $\leq 150 \mathrm{mg}$ fluconazole
Exposed to $>150 \mathrm{mg}$ fluconazole

$$
\text { Yes, } \boldsymbol{n}(\%)
$$$$
\text { No, } \boldsymbol{n}(\%)
$$

$19488(8.6)$

$19346(99.3)$
$92(0.5)$
$50(0.3)$

$899(0.4)$

$$
\begin{gathered}
890(99.0) \\
5(0.6) \\
4(0.4)
\end{gathered}
$$

$728(0.3)$

$$
\begin{gathered}
723(99.3) \\
3(0.4) \\
2(0.3)
\end{gathered}
$$

3282 (1.5)

$$
\begin{gathered}
3254(99.2) \\
15(0.5) \\
13(0.4)
\end{gathered}
$$$$
625(0.3)
$$

$$
\begin{gathered}
620(99.2) \\
2(0.3)
\end{gathered}
$$

$1179(0.5)$

$$
\begin{gathered}
1166(98.9) \\
8(0.7) \\
5(0.4)
\end{gathered}
$$$$
2203(1.0)
$$

$2185(99.2)$
$12(0.5)$
$6(0.3)$

8281 (3.7)

$$
\begin{gathered}
8223(99.3) \\
37(0.4) \\
21(0.3)
\end{gathered}
$$

207111 (91.4)

$205940(99.4)$
$821(0.4)$
$350(0.2)$

225700 (99.6)

$224396(99.4)$
$908(0.4)$
$396(0.2)$

225871 (99.7)

$224563(99.4)$
$910(0.4)$
$398(0.2)$

223317 (98.5)

222032 (99.4)

$898(0.4)$

$387(0.2)$

225974 (99.7)

$224666(99.4)$
$911(0.4)$
$397(0.2)$

225420 (99.5)

224120 (99.4)

$905(0.4)$

$395(0.2)$

224396 (99.0)

$223101(99.4)$
$901(0.4)$
$394(0.2)$

217063 (96.3)

$217063(99.4)$
$876(0.4)$
$379(0.2)$

Crude OR 95\% CI

Adjusted* OR 95\% CI

Ref.

Ref.

1.19 (0.96-1.48)

$1.08(0.87-1.34)$

$1.51(1.12-2.03)$

$1.30(0.97-1.75)$

Ref.

Ref.

$1.38(0.57-3.35)$

$1.18(0.49-2.86)$

$2.55(0.95-6.84)$

$1.97(0.72-5.39)$

Ref.

Ref.

$1.02(0.33-3.19)$

$1.03(0.33-3.25)$

$1.56(0.39-6.27)$

$1.50(0.37-6.13)$

Ref.

Ref.

1.14 (0.68-1.90)

$0.98(0.58-1.63)$

$2.31(1.33-4.00)$

1.81 (1.04-3.14)

Ref.

Ref.

$0.80(0.20-3.19)$

$0.66(0.16-2.67)$

$2.74(0.88-8.55)$

$1.95(0.60-6.33)$

Ref.

Ref.

$1.71(0.85-3.42)$

$1.70(0.84-3.43)$

$2.41(0.99-5.85)$

$2.30(0.94-5.62)$

Ref.

Ref.

$1.35(0.76-2.40)$

$1.31(0.73-2.32)$

$1.53(0.67-3.47)$

$1.41(0.62-3.23)$

Ref.

Ref.

$1.12(0.80-1.55)$

$1.03(0.74-1.43)$

$1.45(0.93-2.25)$

Note: $\mathrm{Cl}=$ confidence interval, $\mathrm{OR}=$ odds ratio, $\mathrm{LMP}=$ last menstrual period, Ref. $=$ reference category .

*Adjusted for maternal demographic characteristics at the first day of the LMP (maternal age, welfare recipient and rural dweller), use of health care resources in the 6 months before the LMP (emergency visits or hospital admission, visits to general practitioners and specialist physicians), diagnoses of infection in the 6 months before the LMP until the end of the first trimester, maternal comorbidities in the 6 months before the LMP (hypertension, diabetes, asthma, epilepsy, depression and thyroid disorders), intake of folic acid, tobacco dependence, pregnancy follow-up by a gynecologist or obstetrician, use of other medications (other than the study medication and the medications used for the assessment of the maternal comorbidities) and pregnancy in the year before the LMP (regardless of whether it ends with childbirth, induced or spontaneous abortion). 
investigated the association between exposure to fluconazole during the first trimester and risk of spontaneous abortion ${ }^{42}$ or stillbirth. ${ }^{42,43}$

In our study, only exposure to high-dose fluconazole was associated with an increased risk of cardiac septal closure anomalies. Exposure to low-dose fluconazole did not increase overall major congenital malformations or specific organ system malformations.

Safety studies conducted in Denmark found that use of oral fluconazole in pregnancy was not associated with an increased risk of major congenital malformation overall, but was associated with an increased risk of tetralogy of Fallot (adjusted OR 3.16, 95\% Cl 1.49-6.71; 7 exposed cases). ${ }^{44}$ Smaller observational studies in Europe did not identify an association between use of oral fluconazole during pregnancy and risk of major congenital malformation. ${ }^{42,43,45-47}$ However, these results may not be generalizable to non-Scandinavian populations, as there are considerable variations in rates of birth defects and spontaneous abortions among North American and European people.

Data from the US National Birth Defect Registry have shown that exposure to low-dose fluconazole during the first trimester increased the risk of cleft lip or cleft palate (OR 5.53, 95\% Cl 1.68$18.24 ; 6$ exposed cases) and D-transposition of the great arteries (OR 7.56, 95\% Cl 1.22-35.45; 3 exposed cases). ${ }^{32}$ However, this study was conducted in a volunteer-based, selective sample, and its result may thus not be generalizable to public Medicaid recipients, a population potentially at increased risk of the occurrence of birth defects.

The strengths of our study include use of a population-based prospective pregnancy cohort with linkage of data on the individual level, which allowed for analyses of a large number of pregnancies with detailed information regarding exposure, outcomes and potential confounders. Data on filled prescriptions were used to determine exposure to medication, as is routine in other studies..$^{40,43,44,47}$ Data on filled prescriptions in the Quebec Pregnancy Cohort, ${ }^{34}$ major congenital malformation outcomes ${ }^{38}$ and gestational age ${ }^{21}$ have been validated.

\section{Limitations}

The main limitation of our study is missing information on potential confounders such as smoking, use of over-the-counter folic acid and alcohol intake. Tobacco and alcohol dependence and prescribed folic acid were used as proxies for these variables. We do not have microbiology data to confirm Candida infection. We have used ICD-9 and ICD-10 codes, combined with data on filled prescriptions, for other antifungals and antibiotics. In a validation study of these codes in a pediatric population (22167 discharges between May and October 2007 in the Pediatric Health Information System database, which contains clinical and billing information from 43 children's hospitals in the United States), using microbiological data as gold standard, the positive predictive value for ICD-9 codes for candidemia (112.5 and 112.89 ) was $62 \%$, and negative predictive value was $99.9 \% .{ }^{48}$ These results show that the ICD-9 codes for Candida capture about $60 \%$ of cases, but they are highly specific (more than 99\%). In the absence of absolute validity, we prefer high specificity, which renders conservative estimates. Given our use of both diagnostic codes and filled prescription data, we are confident that misclassification, if present, is minimal, because our data on filled prescriptions were validated. ${ }^{34}$

Because the databases include only pregnant women insured by the Quebec Prescription Drug Insurance program, generalizability of results to those insured by private drug insurance could be affected. However, validation studies have shown that pregnant women who are publicly insured have characteristics and comorbidities similar to those who have private medication insurance. ${ }^{23}$

We included only clinically detected spontaneous abortion. Therefore, if the use of fluconazole was associated with an increased risk of spontaneous abortion that was not clinically detected, our findings would underestimate the true risk. However, if no association was found between the use of fluconazole and the risk of spontaneous abortion that was not clinically detected, any misclassification resulting from the noninclusion of undetected spontaneous abortion would be nondifferential and our estimates should remain conservative. The prevalence of spontaneous abortion in our study population (around $7 \%$ ) is lower than the reported $15 \%$ of clinically recognized pregnancies. ${ }^{49}$ Given that we could not differentiate women with unwanted pregnancies from those who terminated their pregnancy because they had a prenatal diagnosis of major anomalies, we excluded all women with an induced abortion, hence potentially underestimating the risk of spontaneous abortions.

Finally, our observed prevalence of major congenital malformation was $8.6 \%$. This is higher than other population reports of $3 \%-5 \%,{ }^{50}$ a recognized difference that is attributed to the founder genetic effect in the Quebec population. ${ }^{20,51}$ Although our baseline prevalence of major congenital malformations is high, it does not differ among our comparison groups, and therefore does not invalidate our findings.

\section{Conclusion}

Maternal exposure to fluconazole during pregnancy has been shown to be associated with an increased risk of spontaneous abortion, and the risk of anomalies of cardiac septal closure among users of high-dose (> $150 \mathrm{mg}$ ) fluconazole during the first trimester of pregnancy. These findings are consistent with other studies in the literature, but require replication.

\section{References}

1. Georgopapadakou NH, Dix BA, Smith SA, et al. Effect of antifungal agents on lipid biosynthesis and membrane integrity in Candida albicans. Antimicrob Agents Chemother 1987;31:46-51.

2. Keber R, Motaln H, Wagner KD, et al. Mouse knockout of the cholesterogenic cytochrome P450 lanosterol 14alpha-demethylase (Cyp51) resembles AntleyBixler syndrome. J Biol Chem 2011;286:29086-97.

3. Porter FD, Herman GE. Malformation syndromes caused by disorders of cholesterol synthesis. J Lipid Res 2011;52:6-34.

4. Cotch MF, Hillier SL, Gibbs RS, et al. Epidemiology and outcomes associated with moderate to heavy Candida colonization during pregnancy. Vaginal Infections and Prematurity Study Group. Am J Obstet Gynecol 1998;178:374-80.

5. Campomori A, Bonati M. Fluconazole treatment for vulvovaginal candidiasis during pregnancy. Ann Pharmacother 1997;31:118-9.

6. Eckert LO. Clinical practice. Acute vulvovaginitis. N Engl J Med 2006;355:1244-52.

7. Tooley PJ. Patient and doctor preferences in the treatment of vaginal candidosis. Practitioner 1985;229:655-60.

8. van Schalkwyk J, Yudin MH; Infectious Disease Committee. Vulvovaginitis: screening for and management of trichomoniasis, vulvovaginal candidiasis, and bacterial vaginosis. J Obstet Gynaecol Can 2015;37:266-74.

9. Sobel JD. Vulvovaginal candidosis. Lancet 2007;369:1961-71.

10. Lee BE, Feinberg M, Abraham JJ, et al. Congenital malformations in an infant born to a woman treated with fluconazole. Pediatr Infect Dis J 1992;11:1062-4.

11. Pursley TJ, Blomquist IK, Abraham J, et al. Fluconazole-induced congenital anomalies in three infants. Clin Infect Dis 1996;22:336-40.

12. Aleck KA, Bartley DL. Multiple malformation syndrome following fluconazole use in pregnancy: report of an additional patient. Am J Med Genet 1997;72:253-6. 
13. Lopez-Rangel E, Van Allen MI. Prenatal exposure to fluconazole: an identifiable dysmorphic phenotype. Birth Defects Res A Clin Mol Teratol 2005;73:919-23.

14. Tiboni GM. Second branchial arch anomalies induced by fluconazole, a bis-triazole antifungal agent, in cultured mouse embryos. Res Commun Chem Pathol Pharmacol 1993;79:381-4.

15. Menegola E, Broccia ML, Di Renzo F, et al. Pathogenic pathways in fluconazoleinduced branchial arch malformations. Birth Defects Res A Clin Mol Teratol 2003;67:116-24

16. Adachi M, Tachibana K, Asakura Y, et al. Compound heterozygous mutations of cytochrome P450 oxidoreductase gene (POR) in two patients with Antley-Bixler syndrome. Am J Med Genet A 2004;128A:333-9.

17. Sexually transmitted diseases treatment guidelines 2002. MMWR Recomm Rep 2002;51:1-78.

18. Sexually transmitted diseases treatment guidelines, 2006 [published erratum in MMWR Recomm Rep 2006;55:997]. MMWR Recomm Rep 2006;55:1-94.

19. US Food and Drug Administration Drug Safety Communication: use of long-term, high-dose Diflucan (fluconazole) during pregnancy may be associated with birth defects in infants. Rockville (MD); 2011. Available: www.fda.gov/Drugs/DrugSafety/ ucm266030.htm (accessed 2014 Oct. 22).

20. Bérard A, Sheehy $O$. The Quebec Pregnancy Cohort - prevalence of medication use during gestation and pregnancy outcomes. PLoS One 2014;9:e93870.

21. Vilain A, Otis S, Forget A, et al. Agreement between administrative databases and medical charts for pregnancy-related variables among asthmatic women. Pharmacoepidemiol Drug Saf 2008;17:345-53.

22. Régie de l'Assurance Maladie du Québec. Rapport d'études et de statistiques. Quebec: Gouvernement du Quebec; 2015. Available: www4.prod.ramq.gouv.qc.ca/IST/ CD/CDF_DifsnlnfoStats/CDF1_CnsullnfoStatsCNC_iut/DifsnInfoStats.aspx?ETAPE_ COUR=2\&LANGUE=fr-CA (accessed 2018 July 28).

23. Bérard A, Lacasse A. Validity of perinatal pharmacoepidemiologic studies using data from the RAMQ administrative database. Can J Clin Pharmacol 2009;16:e360-9.

24. Nakhai-Pour HR, Broy $P$, Sheehy $\mathrm{O}$, et al. Use of nonaspirin nonsteroidal antiinflammatory drugs during pregnancy and the risk of spontaneous abortion. CMAJ 2011;183:1713-20.

25. Nakhai-Pour HR, Broy P, Berard A. Use of antidepressants during pregnancy and the risk of spontaneous abortion. CMAJ 2010;182:1031-7.

26. Bérard A, Zhao JP, Sheehy O. Antidepressant use during pregnancy and the risk of major congenital malformations in a cohort of depressed pregnant women: an updated analysis of the Quebec Pregnancy Cohort. BMJ Open 2017;7:e013372.

27. Bérard A, Sheehy $O$, Girard S, et al. Risk of preterm birth following late pregnancy exposure to NSAIDs or COX-2 inhibitors. Pain 2018;159:948-55.

28. Rendall MS, Ghosh-Dastidar B, Weden MM, et al. Multiple imputation for combinedsurvey estimation with incomplete regressors in one but not both surveys. Sociol Methods Res 2013;Nov 1:42.

29. Kulaga $\mathrm{S}$, Zargarzadeh $\mathrm{AH}$, Berard A. Prescriptions filled during pregnancy for drugs with the potential of fetal harm [published erratum in BJOG 2010;117:373]. BJOG 2009;116:1788-95.

30. Data quality, concepts and methodology: definitions. Ottawa: Statistics Canada; modified 2012 Dec. 20. Available: www150.statcan.gc.ca/n1/pub/84f0210x /2008000/technote-notetech1-eng.htm (accessed 2018 Nov. 16).

31. Berard A, Sheehy O, Kurzinger ML, et al. Intranasal triamcinolone use during pregnancy and the risk of adverse pregnancy outcomes. J Allergy Clin Immunol 2016;138:97-104.e7.
32. Howley MM, Carter TC, Browne ML, et al. Fluconazole use and birth defects in the National Birth Defects Prevention Study. Am J Obstet Gynecol 2016;214:657 e1-9.

33. Bleyl SB, Schoenwolf GC. What is the timeline of important events during pregnancy that may be disrupted by a teratogenic exposure? In: Teratology primer, 3rd edition; Reston VA: Teratology Society; 2017. Available: www.teratology.org/primer/ Teratogenic-Exposure.asp (accessed 2018 Nov. 16).

34. Zhao JP, Sheehy O, Gorgui J, et al. Can we rely on pharmacy claims databases to ascertain maternal use of medications during pregnancy? Birth Defects Res 2017;109:423-31.

35. International statistical classification of diseases and related health problems, tenth revision, volumes 1 and 2 (ICD-10). Geneva: World Health Organization; 1992.

36. Principles and recommendations for a vital statistics system. Statistical papers, series M, No. 19, Rev. 1. New York: United Nations; 1974.

37. Muanda FT, Sheehy O, Berard A. Use of antibiotics during pregnancy and risk of spontaneous abortion. CMAJ 2017;189:E625-33.

38. Blais L, Berard A, Kettani FZ, et al. Validity of congenital malformation diagnostic codes recorded in Quebec's administrative databases. Pharmacoepidemiol Drug Saf 2013;22:881-9.

39. Glickman ME, Rao SR, Schultz MR. False discovery rate control is a recommended alternative to Bonferroni-type adjustments in health studies. J Clin Epidemiol 2014;67:850-7.

40. Mølgaard-Nielsen D, Svanstrom H, Melbye M, et al. Association between use of oral fluconazole during pregnancy and risk of spontaneous abortion and stillbirth. JAMA 2016;315:58-67.

41. Pasternak B, Wintzell V, Furu K, et al. Oral fluconazole in pregnancy and risk of stillbirth and neonatal death. JAMA 2018;319:2333-5.

42. Mastroiacovo P, Mazzone T, Botto LD, et al. Prospective assessment of pregnancy outcomes after first-trimester exposure to fluconazole. Am J Obstet Gynecol 1996;175:1645-50.

43. Nørgaard M, Pedersen L, Gislum M, et al. Maternal use of fluconazole and risk of congenital malformations: a Danish population-based cohort study. J Antimicrob Chemother 2008;62:172-6.

44. Mølgaard-Nielsen D, Pasternak B, Hviid A. Use of oral fluconazole during pregnancy and the risk of birth defects. N Engl J Med 2013;369:830-9.

45. Inman W, Pearce G, Wilton L. Safety of fluconazole in the treatment of vaginal candidiasis. A prescription-event monitoring study, with special reference to the outcome of pregnancy. Eur J Clin Pharmacol 1994;46:115-8.

46. Jick SS. Pregnancy outcomes after maternal exposure to fluconazole. Pharmacotherapy 1999;19:221-2.

47. Sorensen HT, Nielsen GL, Olesen C, et al. Risk of malformations and other outcomes in children exposed to fluconazole in utero. Br J Clin Pharmacol 1999;48:234-8.

48. Asti L, Newland J, Zerr D, et al. Multi-center validation of ICD-9 codes for candidemia in a pediatric population [abstract]. Proceedings from Session 67: Infections in Pediatric \& Perinatal Populations, 561. Arlington (VA): Infectious Disease Society of America; 2010 Oct. 22.

49. Ford HB, Schust DJ. Recurrent pregnancy loss: etiology, diagnosis, and therapy. Rev Obstet Gynecol 2009;2:76-83.

50. Egbe AC. Birth defects in the newborn population: race and ethnicity. Pediatr Neonatol 2015;56:183-8.

51. Zhao JP, Sheehy O, Berard A. Regional variations in the prevalence of major congenital malformations in Quebec: the importance of fetal growth environment. J Popul Ther Clin Pharmacol 2015;22:e198-210.
Competing interests: Anick Bérard reports receiving grants from the Canadian Institutes of Health Research (the Canadian Network for Advanced Interdisciplinary Methods for comparative effectiveness research), the Fonds de la recherche du Québec-santé, and the Réseau québécois de recherche sur les médicaments, during the conduct of the study. No other competing interests were declared.

This article has been peer reviewed.

Affiliations: Research Centre (Bérard, Sheehy, Zhao, Gorgui), CHU Sainte-Justine; Faculty of Pharmacy (Bérard, Gorgui), University of Montreal; Faculty of Medicine (Bernatsky, Moura), McGill University; Faculty of Medicine, Department of Clinical Epidemiology (Abrahamowicz), McGill University, Montréal, Que.

Contributors: Anick Bérard obtained funding and data as well as ethics approval. Odile Sheehy and Anick Bérard performed the statistical analyses. Anick Bérard and Jin-Ping Zhao wrote the first draft of the manuscript. All authors wrote the study protocol, interpreted results, critically reviewed the manuscript for important intellectual content, gave final approval of the version to be published and agreed to be accountable for all aspects of the work.

Funding: This study was funded by the Canadian Institutes of Health Research (Canadian Network for Advanced Interdisciplinary Methods for comparative effectiveness research) and Fonds de la recherche du Québec-Santé, and the Réseau québécois de recherche sur les médicaments. The funders of the study had no role in the study design, in the collection, analysis and interpretation of data; in the writing of the report; and in the decision to submit the article for publication.

Data sharing: Researchers interested in accessing the data set used in this study may contact the corresponding author.

Accepted: Jan. 22, 2019

Correspondence to: Anick Bérard, anick.berard@umontreal.ca 